\title{
Non-secretory multiple myeloma with lytic bone lesions about a new observation
}

\author{
M. El Euch, F. Ben Fredj Ismail, A. Rezgui, M. Karmani, F. Derbali, R. Amri, C. Laouani-Kechrid
}

Department of Internal Medicine, Sahloul Hospital, Sousse, Tunisia Email: bfi.fatma@yahoo.fr

Received 4 April 2012; revised 4 May 2012; accepted 31 July 2012

\begin{abstract}
Non-secretory myeloma is a rare variety of multiple myeloma. Classical techniques of chronic secretion's research don't find any immunoglobulin monoclonal peak in the patient's blood. Lytic bone lesions are rare in this type of myeloma. We report the case of a patient in whom we confirmed multiple myeloma by bone marrow aspiration and we have classified stage III of Durie and Salmon in view of hypercalcemia, anemia, and lytic lesions observed. However, we could not isolate a secretion of monoclonal immunoglobulin in blood but urinary secretion was evident by proteinuria and urinary light chains. The radiographs of our patient found diffuse osteolysis and practice of sternal puncture confirmed multiple myeloma. Our case is original because of rarity on non secretory myeloma particularly with diffuse osteolytic lesion.
\end{abstract}

Keywords: Non-Secretory Myeloma; Immunoglobulin; Hypercalcemia; Anemia; Lytic Bone Lesions

\section{INTRODUCTION}

The non-secreting myeloma was first described in 1958 and presented only $1 \%$ of all myeloma [1]. Cereda et al. estimate that by definition, during multiple myeloma, the lack of blood secretion makes retain the form of nonsecretory myeloma. Lytic bone lesions are rare in this type of myeloma [2].

\section{AIM}

We report the rare case of 56 years old patient with a non-secretory myeloma and multiple radiological lytic bone lesions.

\section{OBSERVATION}

56 years old patient with a history of bronchiectasis secondary to recurrent infections since childhood was admitted for exploration of an humerus' pathological fracture. The patient had five months before fatigue, anorexia and weight loss. Bone pain of ribs and arms settled secondarily. The patient had neither headaches, nor joint pain, or fever or polyuropolydipsia syndrome. The exam found a cachectic patient of $45 \mathrm{~kg}$, height of $1.65 \mathrm{~m}$, BMI of $17 \mathrm{~kg} / \mathrm{m}^{2}$, conjunctival pallor with a blood pressure of $110 / 60 \mathrm{mmHg}$ and a heart rate of 90 beats minute. No organomegaly was found and all peripheral lymph nodes were free. The left limb was immobilized because of the fracture with pain when pressure rib bone and the joints were painless. Neurological examination was without abnormalities. Diagnoses mentioned were either a primary bone tumor including multiple myeloma or bone metastases. Radiological examinations found diffuse osteolytic lesions especially at the $\mathrm{X}$-ray of the arm (Figure 1). Chest radiography showed diffuse osteolytic lesions of ribs and clavicles, parenchymal distension, alveolo interstitial syndrome with bilateral sequelae related to its bronchiectasis (Figure 2). Skull radiography showed gaps in the punch and macrogeodes strongly suggesting multiple myeloma (Figure 3). Laboratory investigations showed an inflammatory syndrome with a sedimentation rate $>140$ in the first hour, the serum protein electrophoresis showed an hyper $\alpha 2$ globulin at $16 \mathrm{~g} / 1$, hypo albumin $32.8 \mathrm{~g} / \mathrm{l}, \alpha 1$ globulin at 7 $\mathrm{g} / 1, \beta 1$ globulin at $6.2 \mathrm{~g} / 1$, a $\beta 2$ globulin at $5.5 \mathrm{~g} / \mathrm{l}$, and gamma globulin $11.6 \mathrm{~g} / \mathrm{l}$ without monoclonal peak. The count of blood cell lines showed a normocytic normochromic anemia with $\mathrm{Hb} 10.2 \mathrm{~g} / \mathrm{dl}, \mathrm{MCV} 90.1 \mathrm{fl}$ and $\mathrm{MCH}$ at 28.7; white elements, platelets and hemostatic parameters were normal. Creatinine was at $103 \mu \mathrm{mol} / \mathrm{l}$, serum calcium at $2.7 \mu \mathrm{mol} / 1$, serum uric acid at $403 \mu \mathrm{mol} / 1$ and $\beta 2$ microglobulin at $7002 \mu \mathrm{g} / \mathrm{l}$ (normal value $<1310$ $\mu \mathrm{g} / \mathrm{l}$.

The quantitation of serum immunoglobulins was as follows: $\operatorname{Ig} G=15.3 \mathrm{~g} / 1$ (normal value between 6.9 and $16.2 \mathrm{~g} / 1$ ), $\operatorname{Ig} A=2.5 \mathrm{~g} / 1$ (normal value between 0,7 and $3.8 \mathrm{~g} / 1$ ), $\operatorname{Ig} M=0.29 \mathrm{~g} / 1$ (normal value between 0.6 and $2.6 \mathrm{~g} / 1)$. As to the urinalysis proteinuria was found at $2.61 \mathrm{~g} / 24 \mathrm{~h}$ and urinary light chains $>8 \mathrm{mg} / \mathrm{dl}$. The sternal puncture confirmed the diagnosis of multiple myeloma by demonstrating dystrophic medullary plasmacytosis 


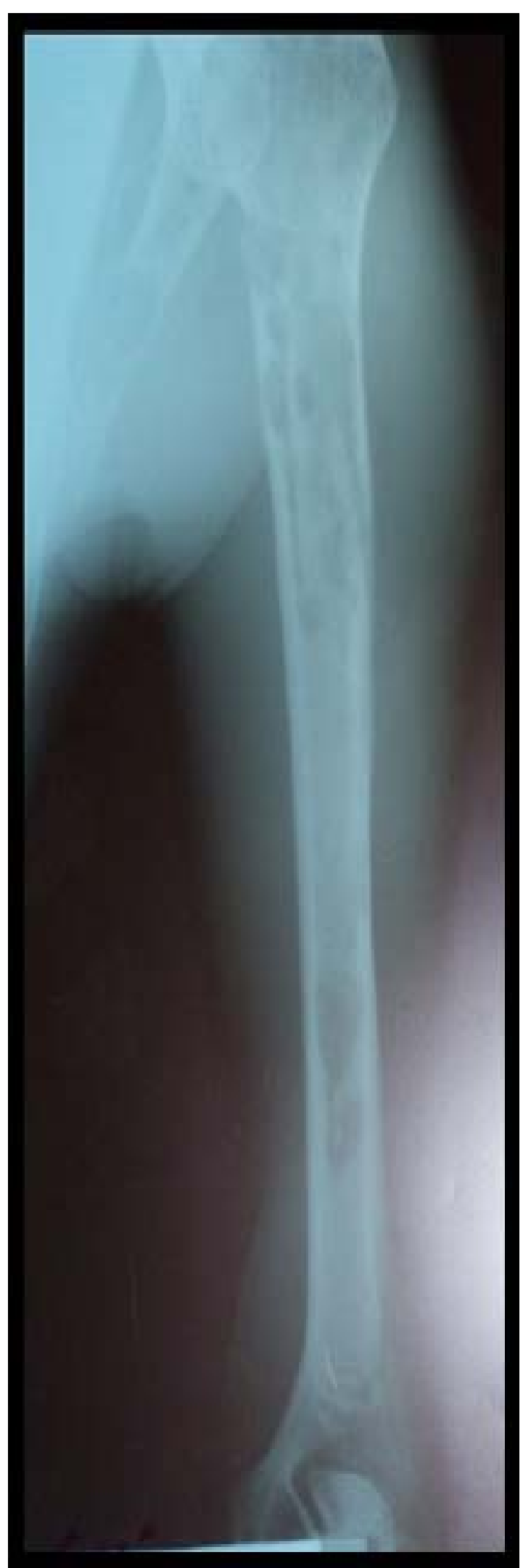

Figure 1. Radiograph of the right arm showing osteolytic bone at the humeral shaft.

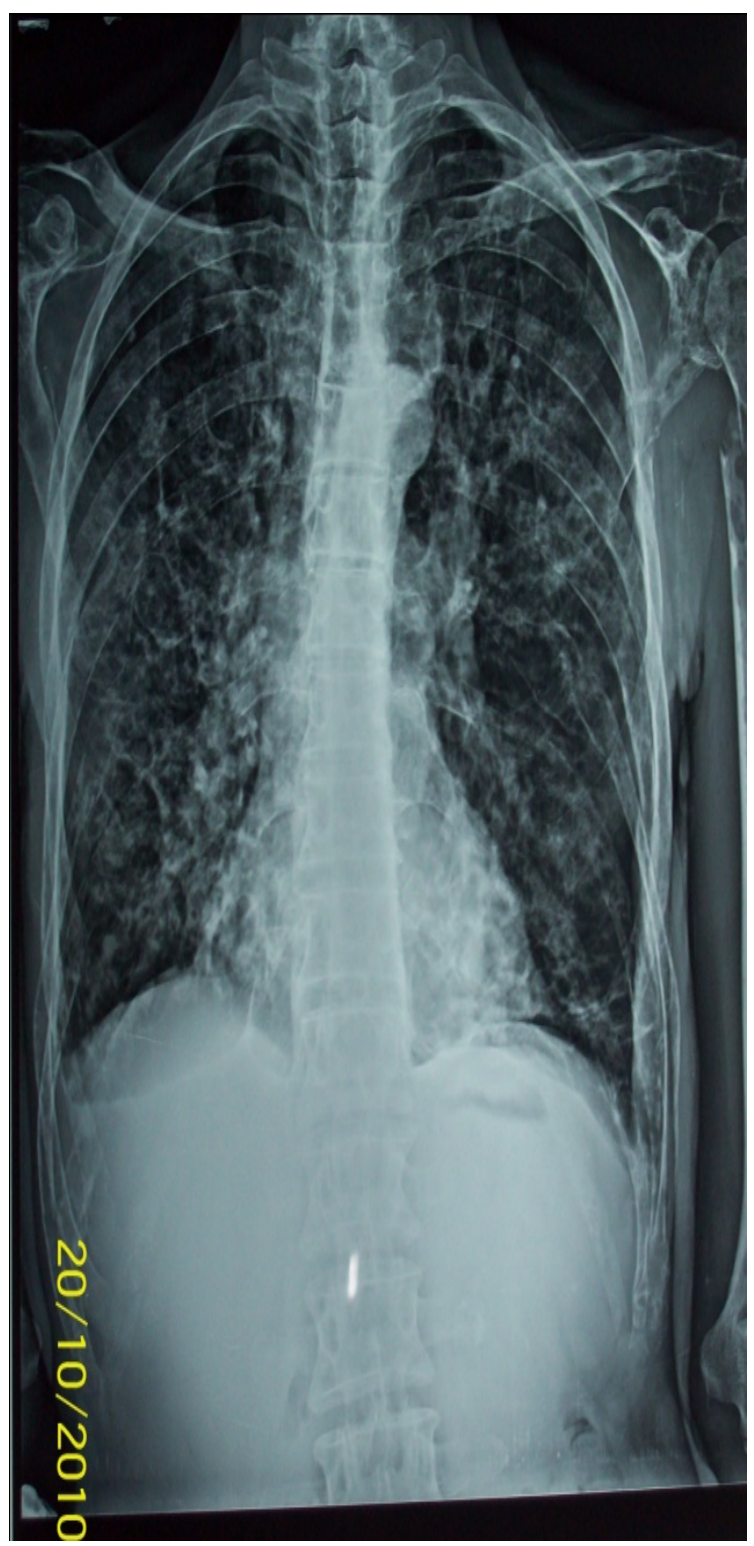

Figure 2. Chest radiograph: sequelae of parenchymal abnormalities and DDB with costal and clavicular osteolysis.

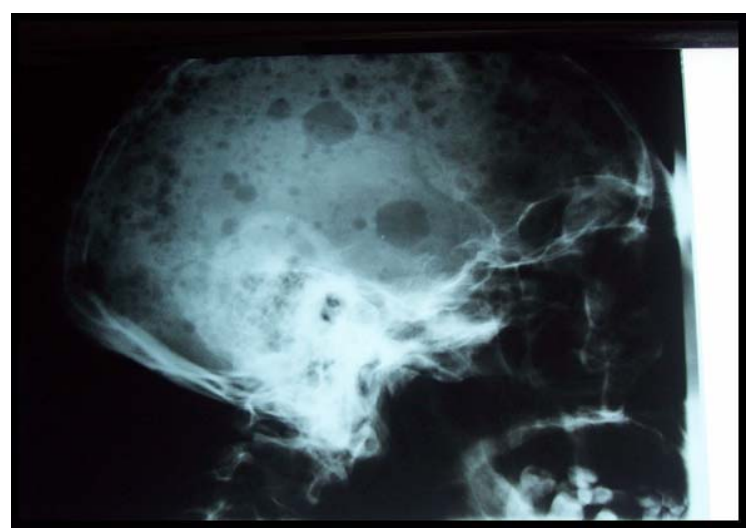

Figure 3. Skull radiograph showing diffuse bone defects of various sizes with macrogeodes. 
at $29 \%$. The patient was transferred to the department of hematology and he is benefiting of classic chemotherapy with sufficient response.

\section{DISCUSSION}

Non-secreting myeloma was first described in 1958, and a retrospective study of 869 cases of multiple myeloma conducted in 1975 suggested that the prevalence of non-secretory form was $1 \%$ [1]. Our patient had multiple myeloma confirmed by sternal puncture and classified stage III of Durie and Salmon in view of hypercalcemia, anemia, and lytic lesions observed. We could not isolate a secretion of monoclonal immunoglobulin in blood but urinary secretion was evident by proteinuria and urinary light chains. Cereda et al. estimate that by definition, during the non-secretory myeloma any blood or urine monoclonal immunoglobulin cannot be identified, this has not been selected and subsequently the lack of blood secretion makes retain the form of non-secretory myeloma [2]. Diffuse osteolytic lesions were often observed within the secretory disease and rarely in the non-secreting form. A review of the prevalence of bone lesions observed in 33 patients with non-secreting myeloma found that only 4 cases had diffuse bone demineralization, however, nobody has presented a biologically hypercalcemia [3]. Osteoclasts stimulation by osteoclast activating factor seems to be the main mechanism of bone resorption. Plasmacytic malignant cells secrete monokines and lymphokine-like molecules independently of secreting immunoglobulins, at distance and not only at the bone site [4]. In about $1 \%-2 \%$ of cases of multiple myeloma conventional techniques of immunoelectrophoresis showed no band of serum immunoglobulin $[3,4]$. These non-secretory myeloma variants appear to be particularly aggressive, with a reported median survival of less than seven and a half years in published series [5].

The overall poor prognosis of non-secreting myeloma was confirmed by other authors [6-8]. The absence of detectable blood secretion, making monitoring of treatment response more difficult. Hobbs suggests that protein electrophoresis does not detect blood immunoglobulin in myeloma when at least $20 \mathrm{~g}$ of tumor is present [6]. The pathogenesis of this lack of secretion has been the subject of much debate. In some cases intracellular immunoglobulins were found by immunofluorescence $[9$, 10], indicating a defect in immunoglobulin secretion rather than production, while in other cases no intracellular immunoglobulin was found [7-10]. Putham and Miyake suggest that malignant cells in some cases synthesize or excrete a pathological immunoglobulin undetectable by conventional techniques [11]. The diagnosis of amyloidosis worn during a non-secreting myeloma raises the possibility that malignant cells can secrete immunoglobulin in quantities too small to be detected by conventional techniques [5]. In vitro, the secretion of small amounts of immunoglobulins has recently been demonstrated in non-secreting myeloma [12]. In our case, the presence of urinary light chains strongly supports the possibility of a tumor secretion even in the absence of blood detection. Other studies using idiotypic antibodies are underway. Therapeutic protocol of treatment is the same than secretory myeloma [1].

\section{CONCLUSION}

Non-secretory multiple myeloma is certainly a rare entity. A sternal puncture is necessary when clinical and radiographic sings make suspect myeloma, even in lack of blood and urinary secretion. This is important to ovoid missing a serious diagnosis.

\section{REFERENCES}

[1] Chauberta, A.B., et al. (2005) Myélome multiple. Swiss Medical Forum, 5, 309-316.

[2] Cereda, J.M., Ayres, J. and Gibson, T. (1982) Non-excretory myeloma. British Medical Journal, 285, 715-716. doi:10.1136/bmj.285.6343.715

[3] Osserman, E.F. and Takatsuki, K. (1963) Plasma cell myeloma: Gamma globulin synthesis and structure. Medicine, 42, 375-384.

[4] Hobbs, J.R. (1969) Immunochemical classes of myelomatosis. British Journal of Haematology, 16, 599-606. doi:10.1111/j.1365-2141.1969.tb00440.x

[5] Azar, H.A., Zaino, E.C., Pham, T.D. and Yannopoulos, K. (1972) Non-secretory plasma cell myeloma. American Journal of Clinical Pathology, 58, 618-629.

[6] Hobbs, J.R. (1971) Immunocytoma o' mice an' men. British Medical Journal, 67-72. doi:10.1136/bmj.2.5753.67

[7] River, G.L., Tewksbury, D.A. and Fundenberg, H.H. (1972) Non-secretory multiple myeloma. Blood, 40, 204206.

[8] Bartolini, C., Flamini, G., Logroscino, C., et al. (1980) Non-secretory multiple myeloma: Report of a case. Blood, 56, 898-901.

[9] Hurez, D., Preud'homme, J.L., Seligmann, M. (1970) Intracellular monoclonal immunoglobulin in non-secretory human myeloma. The Journal of Immunology, 104, 263-264.

[10] Joyner, M.V., Cassuto, J.P., Dujardin, P., Schneider, M., Ziegler, G., Euller, L. and Masseyeff, R. (1979) Non-excretory multiple myeloma. British Journal of Haemato$\log y, 43,559-566$. doi:10.1111/j.1365-2141.1979.tb03788.x

[11] Putham, F.W. and Miyake, A. (1958) Proteins in multiple myeloma. Biosynthesis of abnormal proteins. The Journal of Biological Chemistry, 231, 671.

[12] Mabry, R.J., Shelburne, J. and Cohen, H.J. (1977) In vitro 
kinetics of immunoglobulin synthesis and secretion of non-secretory human myeloma cells. Blood, 50, 1031-
1038. 